\title{
Evaluation of fatigue fracture mechanism in a flash butt welding joint of a U75V type steel for railroad applications
}

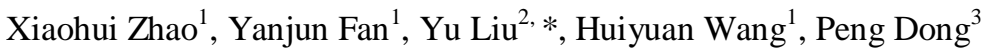 \\ ${ }^{1}$ Key Laboratory of Automobile Materials, School of Materials Science and \\ Engineering, Jilin University, Changchun 130025, China \\ ${ }^{2}$ School of Mechanical Science and Engineering, Jilin University, Changchun 130025, China \\ ${ }^{3}$ School of Materials Science and Engineering, Taiyuan University of Technology, Taiyuan 030024, \\ China \\ (*Corresponding author: Dr. Yu Liu, Tel. +86-0431- 85094687, Fax: +86-0431- 85094687) \\ E-mail: $\underline{\text { liuyuu@jlu.edu.cn }}$
}

\begin{abstract}
Nowadays, U75V steel is widely used in high speed railway construction, and commonly jointed by means of flash butt welding procedure. Considering the fact that fatigue failure is the main failure mode of railways, to ensure an adequate service life of railways, especially railways in coastal areas, this work mainly investigated the fatigue fracture mechanism of flash butt welding joints of U75V rail steel. First, the flash butt welding joints were prepared under two sets of process parameters and certain welding joints were corroded beforehand. Then, the microstructure, hardness, $S-N$ curve and fatigue fracture of welding joints were analyzed in detail. Finally, the fracture mechanism was comprehensively discussed by considering the effect of welding parameters. It was concluded that the fatigue performance of flash welding joint is mainly determined by the upset pressure. Higher upset pressure is conducive to improve the fatigue strength. The fatigue crack source of fractured specimens under the condition of corrosion environment is at interface area and at the subsurface of sample. Meanwhile, the corrosion fatigue life obviously reduces.
\end{abstract}

Keywords: U75V rail steel; Welding joint; Fatigue; Fracture mechanism 


\section{Introduction}

Nowadays, high-speed rail transport is becoming the most important way of carriage in continental countries, especially those with vast territory, not only because it is one of the most efficient transport ways but also for its price advantage and convenience. Yet, the increase of running speed puts forward higher requirements for safety performance. Catastrophic failures can induce accidents like train derailment, which will result in personal injury and material goods losses. In fact, the integrity of railroads becomes more and more important due to the increase in speed. Unfortunately, most studies only focus on the train itself with rails being neglected. Thus, there is great need for research on the safety capability of both trains and railroads.

In general, structural deterioration phenomenon, which is a typically cause for failure of modern rails, commonly involves strain control fatigue and is also related with the mechanical interactions of wagon wheels and rails. In order to meet the need of increasing traffic, speed and axle load, long welding rails are adopted in railway construction. A large amount of welding joints connect each section of the rail to extend thousands of miles. It is well-known that the microstructures of welding joints undergo dramatic changes during welding process, and defects may also appear. Since fatigue failure is the main failure mode of railroads during their service lives, welding joints are often the weakest portions and their quality directly affects the fatigue performance and service life of railroads.

Rails are commonly jointed by means of flash butt welding, which is an 
economical and efficient welding method for connecting plate pieces, proximate matters, pipes and so on. Most of the literatures on flash butt welding mainly concentrate on the welding procedure, the microstructures and mechanical properties of the flash welding joint. For example, Uğur Arabaci et al. investigated the effects of upsetting current time and normalization heat treatment on hardness and tensile strength of X40CrMoV5 1 and Ç1030 steels jointed by flash butt welding ${ }^{[1]}$. Cemil Çetinkaya et al. also applied flash butt welding on $16 \mathrm{MnCr} 5$ chain steel and investigated the mechanical properties of the welding joints ${ }^{[2]}$. Toshio Kuroda et al. carried out flash butt resistance welding experiments on duplex stainless steels and discussed the micro flashing phenomena during heating process as well as the microstructure of bonding interface in flash butt welding joints ${ }^{[3]}$. They further conducted the micro flash butt welding involving duplex stainless steel with Zr-based metallic glass insert and demonstrated the conditions on which the metallurgical bonding can be obtained ${ }^{[4]}$. Wang Xiao-jun et al. carried out experiments to formulate the flash butt welding process of Q235 steel bar ${ }^{[5]}$. In addition, Rowan D. Henderson et al. worked on the photolithographic patterning of conducting polyaniline films via flash welding, and Weibin Wang et al. analyzed the microstructure of DC flash butt welding for an ultra-fine grain steel through FEM simulation ${ }^{[6,7]}$. These efforts have enriched the research data of flash butt welding. However, research on the fatigue properties of flash butt welding joints is limited. Only a few researchers presented the fatigue data, among which contact fatigue data account for a large part. For example, W. Zhong et al. studied the rolling contact fatigue crack growth in U75V as well as 
$\mathrm{U} 71 \mathrm{Mn}$ rails and investigated the relationship between rolling contact fatigue and the wear of high-speed heavy-haul railway ${ }^{[8,9]}$. L.B. Godefroid et al. studied the fatigue failure of flash butt welding rail in detail, and found that fatigue cracks are initiated near the weld bead and spread in a brittle mode, leading to premature fracture of the material $^{[10]}$. W.J. Wang et al. discussed the coupling relationship between oblique fatigue crack and rail wear in curve track by means of field analysis and theoretical calculation $^{[11]}$. They argued that the relationship between rail side rail wear and fatigue crack damage seems to be competitive and restrictive coupling mechanisms.

Aiming to increase the service lifetimes of railroads, present railroad industry is using modern steels with high mechanical strength and wear resistance. U75V and U71Mn steel are widely used for high-speed rail construction in China and other countries in the world because of their high yield strength, tensile strength, etc. Studies based on these types of materials commonly consist of microstructure and technology for heating processing. For instance, Gao Mingxin et al. illustrated the temperature changing rules of $\mathrm{U} 75 \mathrm{~V}$ rail in the cooling process ${ }^{[12]}$. KANG Hao et al. observed the surface temperature change of U75V $60 \mathrm{~kg} / \mathrm{m}$ heavy rail during heat treatment ${ }^{[13]}$. Meanwhile, many other Chinese researchers are in an effort to investigate the fatigue performance of rail steel ${ }^{[8,9,11]}$. ZHONG Ying-hua analyzed the fracture of U71Mn rail welding butt joints on flash welding ${ }^{[14]}$. CHEN Ming-ming et al. investigated the rail fracture of Chengdu-Kunming railway made of material of $\mathrm{U} 71 \mathrm{Mn}^{[15]}$.

It is worth noting that a large proportion of rails are in the coastal areas for 
countries with long coastline. These rails are susceptible to corrosion under the influence of ocean environment. The corrosion effects interact with cyclic loading and do harm to the fatigue properties of rails including welding joints. Currently, no convincing research has been done on the corrosion fatigue of rail steel flash welding joint. To ensure an adequate service life for the rails, this work investigates the fatigue strength of flash butt welding joints of $\mathrm{U} 75 \mathrm{~V}$ rail steel and analyzes the fracture mechanism of conventional fatigue and corrosion fatigue by comprehensively considering the welding process, metallography characteristics, hardness, fracture, $S-N$ curve and corrosion environment of flash butt welding joints.

\section{Experimental procedures}

\subsection{Experimental material and method}

In this study, as-welded joint is butt joint with flash welding. U75V rail steel was used as base metal (BM). Its chemical composition (wt.\%) and mechanical properties are listed in Table 1 and Table 2. The tensile strength and yield strength of this kind of U75V rail steel can reach about $1150 \mathrm{MPa}$ and $600 \mathrm{MPa}$. Meanwhile, this kind of rail steel possesses good ductility in such high strength level steel, but its weldability is just in common level comparing to low carbon steel. The rail steel of high-speed train also has developed rapidly in the world. For example, the EN260 type steel of European Standards, its tensile strength exceeds $880 \mathrm{MPa}$ and elongation exceeds $10 \%$. The carbon steel in the AREMA, its tensile strength exceeds 980MPa and elongation exceeds $10 \%$. It is observed that the performance of U75V type steel has the advanced level in the world. 
The metallographic structure of U75V type steel is shown in Fig. 1. It can be seen from Fig. 1 that the microstructure of base metal contains coarse lamellar pearlite and a small amount of ferrite. Pearlitic structure has non-uniform grain size and uneven layer spacing.

The flash butt joint specimens were made up of two pieces of cuboid base metal with the same size. The size of each cuboid base metal is shown in Fig. 2. In order to avoid the influence of stress concentration caused by surface scratch on fatigue life, all the specimens were ground carefully by sandpaper.

In the present study, the performance of flash butt joint was studied through two welding processes. Their welding parameters are shown in Table 3.

From Table 3 we can see that the main difference between these two welding processes is the upset pressure.

The hardness values of the joint under different process were tested. Models for MH-3 vickers hardness tester was used to measure the hardness value of flash welding joint. A position was tested every $0.2 \mathrm{~mm}$.

\subsection{Corrosion testing}

The railways in coastal areas are often subjected to the erosion of ocean environment. In order to simulate the service environment of railways, the flash butt joint specimens were soaked in corrosive liquid for 450 hours. The best time of 450 hours was obtained through experiments. The sample surface status will have a greater influence on fatigue test if the corrosion time is more than 450 hours. 
The composition of the corrosive liquid is shown in Table $4^{[16]}$. This kind of chemical composition is the same as that of seawater of Tianjin Newport in China.

\subsection{Fatigue testing}

Fatigue tests on the U75V rail steel flash welding joint were performed. All tension-tension fatigue tests were carried out under constant amplitude loading with stress ratio $R=0.1$ at room temperature. Tests were conducted on $200 \mathrm{kN}$ high frequency fatigue testing machine with static load error within a full measuring range between $\pm 0.2 \%$ and dynamic load error between $\pm 2 \%$. The frequency was resonance frequency determined by the fatigue sample and high frequency fatigue testing machine. The value of frequency in fatigue tests was about $120 \mathrm{~Hz}$.

\section{Results and discussion}

\subsection{The microstructure of flash welding joint}

As observed in Fig. 3 and Fig. 4, the butt joint with flash welding can be divided into four areas: interface area (IA), overheated zone (OZ), recrystallization zone (RZ) and incomplete recrystallization zone (IRZ), except for the base metal (BM). The microstructure was analyzed through a comprehensive consideration of metallographic observation and hardness test. Fig. 3 and Fig. 4 show the specific distribution of hardness values of flash welding joint under the condition of welding process (I) and (II).

Under the condition of welding process (I), the hardness value of heat affected zone on both sides of welding center is higher than that of base metal. Among them, the average hardness of overheated zone, recrystallization zone and incomplete 
recrystallization zone is $698 \mathrm{HV}, 403 \mathrm{HV}$ and $326 \mathrm{HV}$, respectively. The highest hardness is located in the overheated zone, and the value reaches $813 \mathrm{HV}$, which may be caused by lath martensite. The hardness value of welding center decreases obviously comparing with the overheated zone, which is equivalent of a softening zone.

Under the condition of welding process (II), the hardness value of heat affected zone on both sides of welding center is also higher than that of base metal. Among them, the average hardness of overheated zone, recrystallization zone and incomplete recrystallization zone is $392 \mathrm{HV}, 385 \mathrm{HV}$ and $300 \mathrm{HV}$, respectively. The highest hardness is located in the overheated zone, and the value reaches $640 \mathrm{HV}$, which may result from widmanstatten structure and a small amount of martensite in the overheated zone. The hardness value does not significantly decrease in the welding center, i.e., no obvious softening zone appears there. The softening effect of welding seam is due to the burning of alloy elements, decarburization, etc. during the flash process. Thus, the content of carbon and alloy elements which strengthen the welding seam will be greatly lower than that of base metal. This softening effect after welding is very adverse to the actual use of railways. The softened zone of rail welding joint will produce larger abrasion loss during the service process, which will result in the uneven abrasion phenomenon. The uneven abrasion makes welding joint present the characteristics of hollow. The depressed phenomenon will increase the irregularity of seamless line, leads to the deterioration of stress state of welding joint, reduces the service life of welding joint and affects the driving comfort and safety. Comparing Fig. 
3 with Fig. 4, it can be found that the hardness distribution is relatively uniform in Fig. 4, except few local positions in overheated zone. Meanwhile, the softening area of $0.4 \mathrm{~mm}$ in Fig. 3 will reduce the ability of crack resistance at welding seam position.

The OLS3000 laser confocal microscope was adopted to observe the microstructure. The microstructures of flash welding joint based on welding process (I) and (II) were shown in Fig. 5 and Fig. 6.

From Fig. 5 it can be seen that although the interface area is very narrow, the eutectic structure on either side of the interface has already formed, with no obvious dividing line in the interface area, which means that macroscopic defects do not exist at interface area. The microstructure of overheated zone consists of lath martensite and free graphite. The free graphite, however, destroys the continuity of matrix, reduces the carbon content in solid solution, and seriously affects the comprehensive performance of welding joint, especially the toughness, fatigue strength and high temperature strength, which eventually leads to brittle fracture. The microstructure of recrystallization zone is lamellar pearlite and reticular ferrite. Recrystallization zone is equivalent to the normalized processing of base metal, which reduces the size of chunk and the layer spacing of pearlite as well as refines grains. For incomplete recrystallization zone, the microstructure resolution is between fine grain zone and base metal, mainly including pearlite, mixed with a small amount of ferrite structure.

In Fig. 6, the interface area of flash welding joint based on welding process (II) is wider than that of flash welding joint based on welding process (I). This is because the upset pressure of welding process (II) is larger. The microstructure of interface 
area is the same as that of base metal (pearlite+ferrite). The eutectic structure on either side of the interface also has already formed, indicating that the bonding strength of workpiece is very good. The basic microstructure of overheated zone is ferrite (white) and pearlite (black). As the hardness value is higher at local position of overheated zone, the white area also contains a small amount of martensite. In addition, the net-like ferrite is in grain boundary and grows in transgranular direction, which has the characteristics of the westergren structure. The microstructure of recrystallization zone and incomplete recrystallization zone is similar to that of flash welding joint based on welding process (I). Fatigue damage will not be easy to occur in these two areas.

\subsection{Fatigue $S$-N curve}

The stress level and fatigue life together determine the fatigue performance of the sample. The relationship between applied stress and fatigue life is represented in equation (1). The curve based on the equation (1) is the traditional $S$ - $N$ curve.

$$
N=\frac{C}{\Delta \sigma^{m}}
$$

According to $S-N$ curve, the fatigue strength corresponding to a cyclic number can be obtained. Fatigue testing data should be analyzed according to the principle of statistical method established in IIW (International Institute of Welding) ${ }^{[17]}$ by A. Hobbacher. The authorized surviving fraction is $50 \%$, while the confidence is $75 \%$.

Nominal value is calculated as the following process:

1. Calculating all the stress range $\Delta \sigma$ and the cycle index $N$ (in logarithm with the base-number 10) of fatigue testing data points. 
2. Calculating the exponent $\mathrm{m}$ and the constant $\log C$ regressively, using the power function model:

$$
m \log \Delta \sigma+\log N=\log C
$$

Three $S$ - $N$ curves representing the conventional joints based on welding process (I), the corrosion joints based on welding process (II) and the conventional joints based on welding process (II) were shown in Fig. 7. The values of $C$ and $\mathrm{m}$ obtained from fitted $S-N$ curves and Eq. (1) are as presented in Table 5. It can be seen from Fig. 7 that the $S-N$ curve of the conventional joints based on welding process (II) is higher than that of the conventional joints based on welding process (I), which indicates that the fatigue performance of flash welding joint is mainly determined by the upset pressure. In addition, the fatigue strength range of the conventional joints based on welding process (II) corresponding to $1.0 \times 10^{6}$ cycles is $302 \mathrm{MPa}$ and is $215 \mathrm{MPa}$ for the case of welding process (I). According to the comparison of the two kinds of joints, fatigue strength of the conventional joints based on welding process (II) increases by $40.4 \%$. The fatigue strength range of corrosion joints based on welding process (II) corresponding to $1.0 \times 10^{6}$ cycles is $266 \mathrm{MPa}$. The fatigue strength range of corrosion joints decreases by $13.5 \%$ comparing with the conventional joints based on welding process (II). However, the fatigue strength range of corrosion joints is still higher than the conventional joints based on welding process (I).

\subsection{The analysis of conventional fatigue fracture mechanism}

Fig. 8 shows the fatigue fracture location of two kinds of conventional joints. Fracture location of the joints based on welding process (I) is at the weld center line . 
Although the lower upset pressure for welding process (I) can make the eutectic organization form at interface area, the lower bonding strength at the weld center line will become the main position of fatigue crack initiation. Fracture location of the joints based on welding process (II) is at base metal. A closer look shows that the base metal cracks are located within the fixation region in the test machine, which indicates that the fatigue limit would be higher without the additional stress caused by the fixation. However, the vertical degree of fatigue sample is very good and the tension-tension fatigue tests are carried. Thus, the additional stress caused by the fixation has a smaller influence on fatigue life. Meanwhile, fatigue limit is characterized by stress range (not maximum stress) in this study, which further weakens the influence of additional stress on fatigue performance of welding joint. Therefore, we do not consider the effects of additional stress on fatigue performance in this paper.

The mechanism of crack initiation and propagation was examined on the failed samples using SEM. The typical fatigue fracture is divided into three regions: fatigue crack nucleation region, fatigue crack growth region and instantaneous fracture region. These three regions represent three processes of fatigue life. Fig. 9 is the SEM photograph of fatigue fracture for the joints based on welding process (I). This fatigue fracture only contains two regions, which are crack source region and crack propagation. It is because the toughness of this flash welding joint is relatively poor and crack growth rate is much faster. The crack extension soon is full of the whole crossing section. Thus, there is no obvious instantaneous fracture region. 
Fig. 10 is the SEM photograph of fatigue crack nucleation region for the joints based on welding process (I). Fatigue crack nucleation region clearly presents the intergranular fracture mode and the local partial transgranular fracture mode. This model of fatigue crack source is relatively rare. Meanwhile, the area of this crack source is larger. From Fig. 5(IA) we can see that the grain size is coarse and thick. Coarse grains will make the grain boundary strength, plasticity and toughness of interface area decrease. The weak grain boundary is the main reason to form this kind of fatigue crack source. Finally, fatigue crack source forms at grain boundary.

Fig. 11 is the SEM photograph of fatigue crack propagation region for the joints based on welding process (I), where steady state crack growth occurs. The micro-level striations have been observed. Moreover, Fig. 11 also presents the cross striations, which is because the multiple small crack sources extend in different directions. In this fatigue crack propagation region, an inclusion was observed. The energy spectrum analysis was done based on this inclusion (see Fig. 12).

It is clear in Fig. 12 that the inclusion mainly contains $\mathrm{O}, \mathrm{Fe}, \mathrm{Ti}$ and $\mathrm{Al}$. The existence of oxide in the fracture interface is because the lower upset pressure is insufficient to squeeze oxide during welding. The presence of oxide can promote the crack initiation and propagation. Therefore, the fatigue life of the joints based on welding process (I) is lower.

Fig. 13 is the SEM photograph of fatigue crack nucleation region for the joints based on welding process (II). It is found that the place where crack source is initiated contains various defects, including inclusions and surface defects closed to the sample 
surface. This fatigue crack nucleation region does not present the intergranular fracture mode, because the position of fatigue fracture for the joint based on welding process (II) is at base metal. The increase of upset pressure makes the welding interface no longer a weak position.

In view of the fatigue fracture location of welding joint based on process (II) is at the base metal and the toughness of base metal is better than the interface area of welding joint based on process (I). Therefore, fatigue fracture of welding joint based on process (II) presents the instantaneous fracture region. Fig. 14 is the SEM photograph of fatigue crack propagation region and instantaneous fracture region for the joints based on welding process (II). A dividing line between crack propagation region and instantaneous fracture region can be clearly seen. In the fatigue crack propagation region, the micro-level striations have been observed. However, the fan-shaped cleavage pattern exists in the instantaneous fracture region.

The fatigue fracture analysis results indicate that the increase of upset pressure will improve the strength and plasticity of flash welding joint, which is mainly because the increase of upsetting pressure can discharge hot molten metal, reduce the temperature of welding zone and overheated zone and improve the microstructure of interface zone.

\subsection{The fracture mechanism of corrosion fatigue}

Under the comprehensive action of the larger grain size, composition segregation, metallographic structure changes, welding defects and residual tensile stress, the preferential corrosion will happen at weld position (see Fig. 15). Fig. 15 shows that 
the lateral surface of corrosion joint presents black corrosion marks and corrosion's pit. Finally, the combined effect of corrosion and fatigue will reduces the fatigue life of corrosion joint. In Fig. 7, the fatigue strength range of the corrosion joints based on welding process (II) corresponding to $2 \times 10^{6}$ cycles is $266 \mathrm{MPa}$, while it is $302 \mathrm{MPa}$ for the case of non-corrosion joints. Compared with the latter, the former decreases by 13.5\%. Fig. 16 is the SEM photograph of fatigue fracture for the corrosion joints based on welding process (II). This fatigue fracture contains three regions, which are crack source region, crack propagation region and the instantaneous fracture region. These three regions represent three processes of fatigue life. The fatigue crack source of fractured specimens is at interface and at the subsurface of sample. The extension direction of fatigue crack can be clearly observed. Crack begins at certain point and expands around. The direction of crack propagation is indicated by arrow marks.

Fig. 17 is the SEM photograph of three regions corresponding to Fig. 16. Fig. 17a shows that the crack source has obvious corrosion marks and the characterization of intergranular fracture. Fig. $17 \mathrm{~b}$ shows the obvious fatigue striations. The fracture section of instantaneous fracture region has the characteristics of cleavage fracture (see Fig. 17c).

\section{Conclusions}

The present work investigated the fatigue fracture mechanism of flash butt welding joints of $\mathrm{U} 75 \mathrm{~V}$ rail steel by analyzing their microstructure, hardness, $S-N$ curve and fatigue fracture obtained under two welding procedures. The conclusions from this study are as follows: 
(1) The upset pressure is the main factors influencing the mechanical properties of flash welding joint. The appropriate upset pressure makes the eutectic structure on either side of the interface form, which can significantly enhance the bonding strength of welding joint.

(2) The corrosion-fatigue strength of flash welding joints decreased by $13.5 \%$ comparing with conventional-fatigue strength. The fracture location of corrosion-fatigue is at the welding and that of conventional-fatigue is at the base metal. The surface of corrosion joint presents black corrosion marks and corrosion's pit. Finally, the combined effect of corrosion and fatigue reduces the fatigue life of corrosion joint.

(3) With the rapid development of high-speed train field, flash welding as the main connection mode of rail whose security and stability performance should cause more and more attention.

\section{Acknowledgements}

The authors acknowledge the financial support by the National Science Foundation through grant no. 51305160, the Research Funds for the Central Universities (JCKY-QKJC17) and the Youth Scientific Research Fund of Jilin province through grant no. 20130522184JH.

\section{References:}

[1] Arabaci U, Çet 1^nkaya C, Akay A. An investigation of effects of upsetting current 
time and normalization heat treatment on mechanical properties of X40CrMoV5 1 and Ç1030 steels joined by flash butt welding. Materials \& Design 2007; 28: 2351-60.

[2] Çet 1̂nkaya C, Arabaci U. Flash butt welding application on $16 \mathrm{MnCr} 5$ chain steel and investigations of mechanical properties. Materials \& Design 2006; 27: 1187-95.

[3] Kuroda T, Ikeuchi K, Ikeda H. Flash butt resistance welding for duplex stainless steels. Vacuum 2006; 80: 1331-5.

[4] Kuroda T, Shimada M. Micro flash butt welding of super duplex stainless steel with Zr-based metallic glass insert. Vacuum 2009; 83: 153-6.

[5] Wang XJ, Qiao HM, Xia TDg, Zhao WJ. Flash butt welding process of Q235 steel bar, Electric Welding Machine 2014; 44: 86-9.

[6] Henderson RD, Breadmore MC, Dennany L, et al. Photolithographic patterning of conducting polyaniline films via flash welding. Synthetic Metals 2010; 160: 1405-9.

[7] Wang WB, Shi YW, Lei YP, Tian ZL. FEM simulation on microstructure of DC flash butt welding for an ultra-fine grain steel. Journal of Materials Processing Technology 2005; 161: 497-503.

[8] Zhong W, Hu JJ, Li ZB, Liu QY, Zhou ZR. A study of rolling contact fatigue crack growth in U75V and U71Mn rails. Wear 2011; 271: 388-92.

[9] Zhong W, Hu JJ, Shen P, Wang CY, Liu QY. Experimental investigation between rolling contact fatigue and wear of high-speed and heavy-haul railway and 
selection of rail material. Wear 2011; 271: 2485-93.

[10] Godefroid LB, Faria GL, Cândido LC, Viana TG. Fatigue failure of a flash butt welded rail. Procedia Materials Science 2014; 3: 1896-1901.

[11] Wang WJ, Guo J, Liu QY, Zhu MH, Zhou ZR. Study on relationship between oblique fatigue crack and rail wear in curve track and prevention. Wear 2009; 267: $540-4$.

[12] Gao MX, Song H, Jia H, et al. Study on the Temperature Changing Rules of U75V Rail in the Cooling Process. Procedia Engineering 2011; 15: 4579-84.

[13] Kang H, Wu D, Zhao XM. Surface Temperature Change of U75V $60 \mathrm{~kg} / \mathrm{m}$ Heavy Rail During Heat Treatment. Journal of Iron and Steel Research International 2013; 20: 33-7.

[14] Zhong YH. Analysis of fracture of U71Mn rail welded butt joints on flash welding. Electric Welding Machine 2011; 41: 48-52.

[15] Chen MM, Che XL, Huang W, Tan GY. Investigation on rail fracture of Chengdu-Kunming railway. Electric Welding Machine 2004; 34: 46-8.

[16] Hao FL, Li YB, Zhou CQ. Concrete quality control of slip-form construction in winter. Concrete 2001; 12: 48-53.

[17] Hobbacher A. recommendations for fatigue design of welded joints and components. IIW document XIII-2151r1-07/XV-1254r1-07; 2007. 


\section{Figures:}

Fig. 1. The metallographic structure of U75V rail steel

Fig. 2. The size of each cuboid base metal

Fig. 3. The hardness value of flash welding joint based on welding process (I)

Fig. 4. The hardness value of flash welding joint based on welding process (II)

Fig. 5. The microstructure of flash welding joint based on welding process (I)

Fig. 6. The microstructure of flash welding joint based on welding process (II)

Fig. 7. $S$ - $N$ curves of joints under the condition of three welding processes

Fig. 8. Fatigue fracture location of the joints based on welding process (I) and (II)

Fig. 9. SEM photograph of fatigue fracture for the joints based on welding process (I)

Fig. 10. SEM photograph of fatigue crack source region for the joints based on welding process (I)

Fig. 11. SEM photograph of fatigue crack propagation region for the joints based on welding process (I)

Fig. 12. The energy spectrum analysis for fatigue crack propagation region for the joints based on welding process (I)

Fig. 13. SEM photograph of fatigue crack source region for the joints based on welding process (II)

Fig. 14. SEM photograph of fatigue crack propagation region and instantaneous

Fig. 15. The lateral surface of corrosion joint

Fig. 16. SEM photograph of fatigue fracture for the corrosion joint based on welding process (II)

Fig. 17. SEM macrophotograph of three regions corresponding to Fig. 16(a), (b) and (c) 


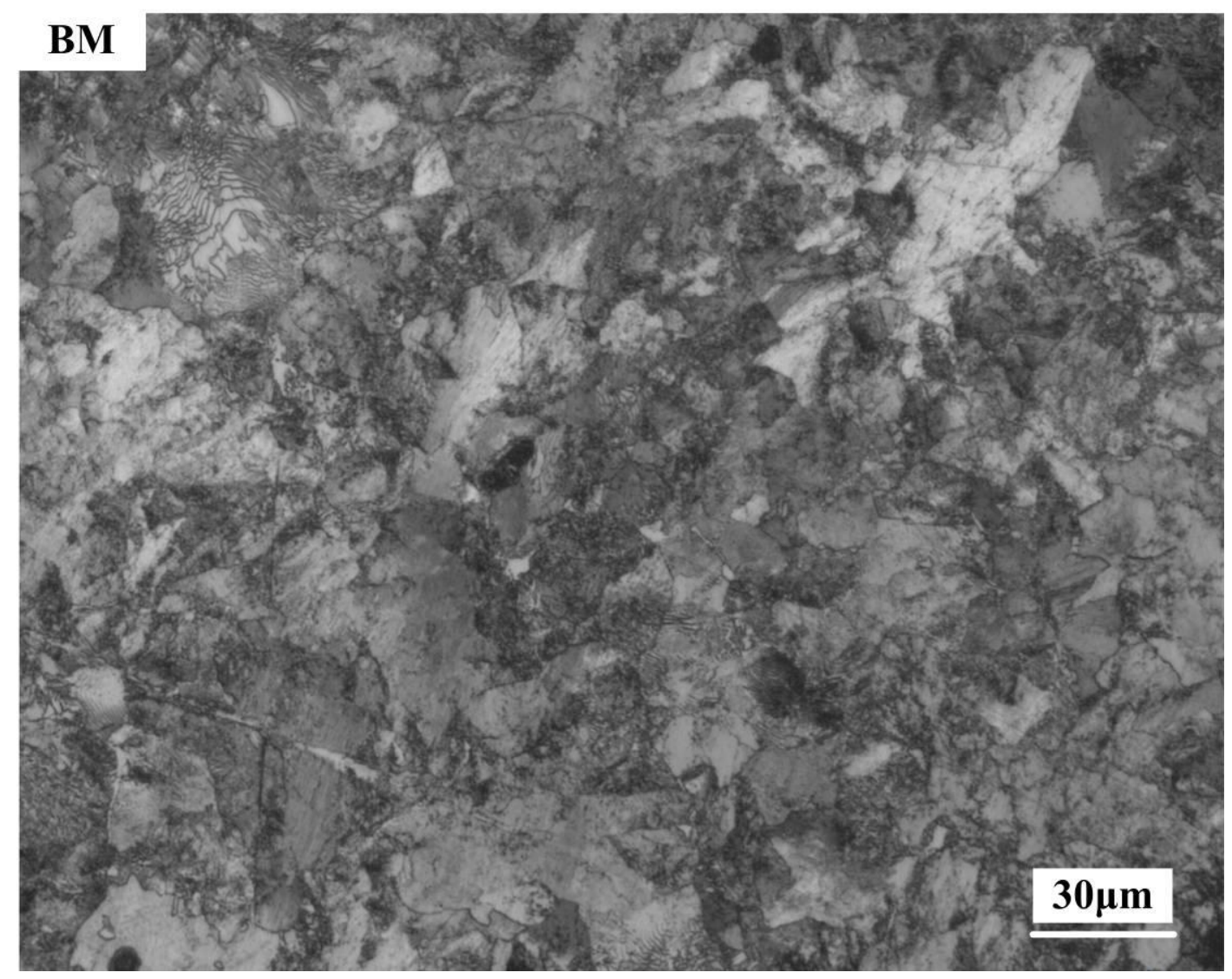

Fig. 1. The metallographic structure of U75V rail steel 
@]

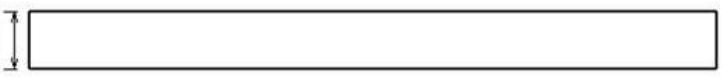

Front view

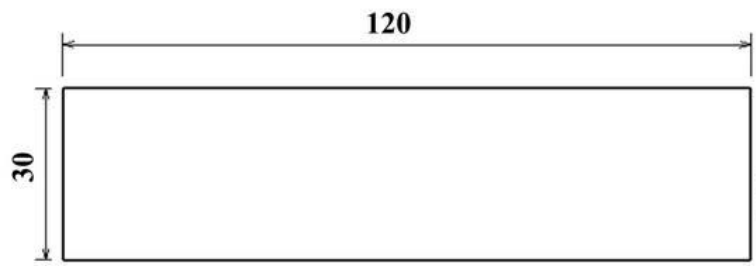

Vertical view

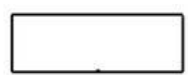

Left View

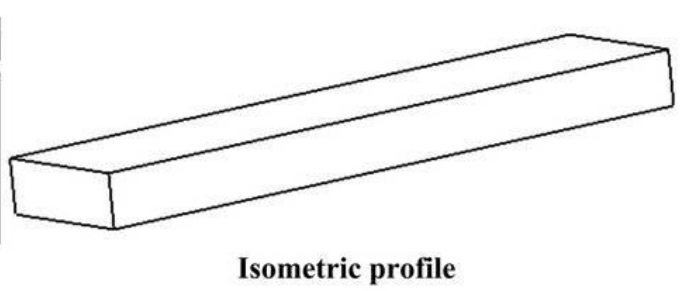

Fig. 2. The size of each cuboid base metal 


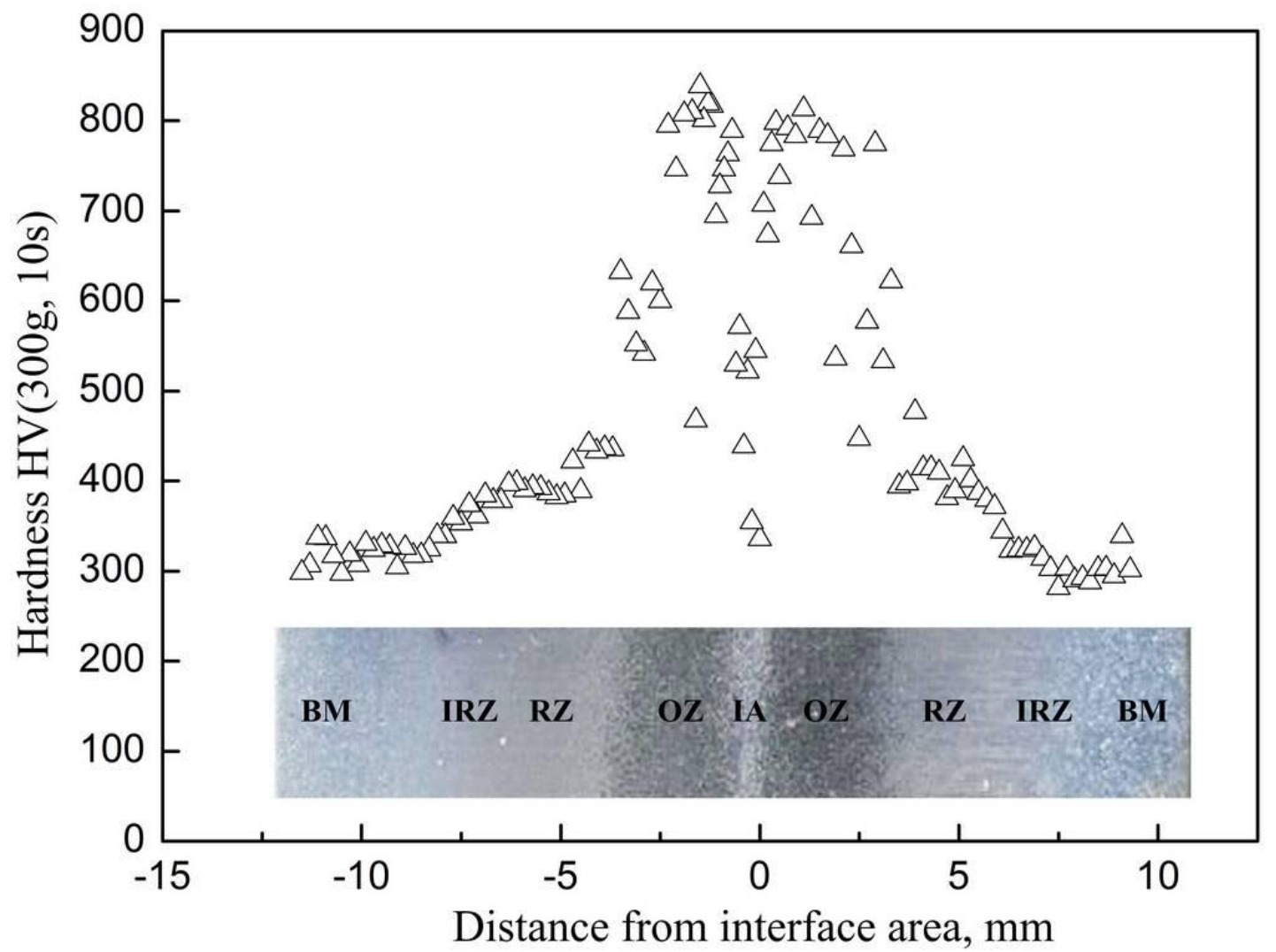

Fig. 3. The hardness value of flash welding joint based on welding process (I) 


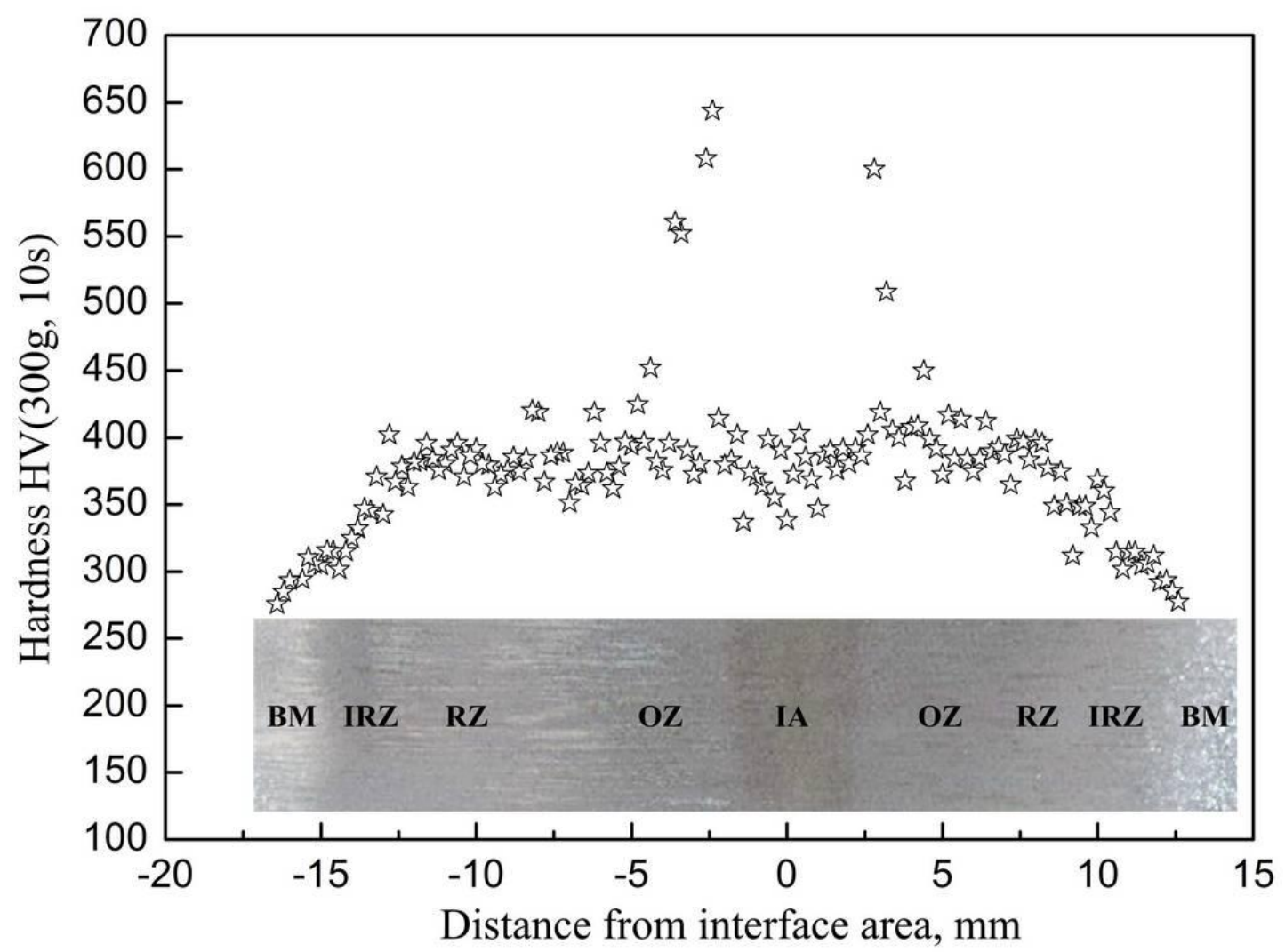

Fig. 4. The hardness value of flash welding joint based on welding process (II) 


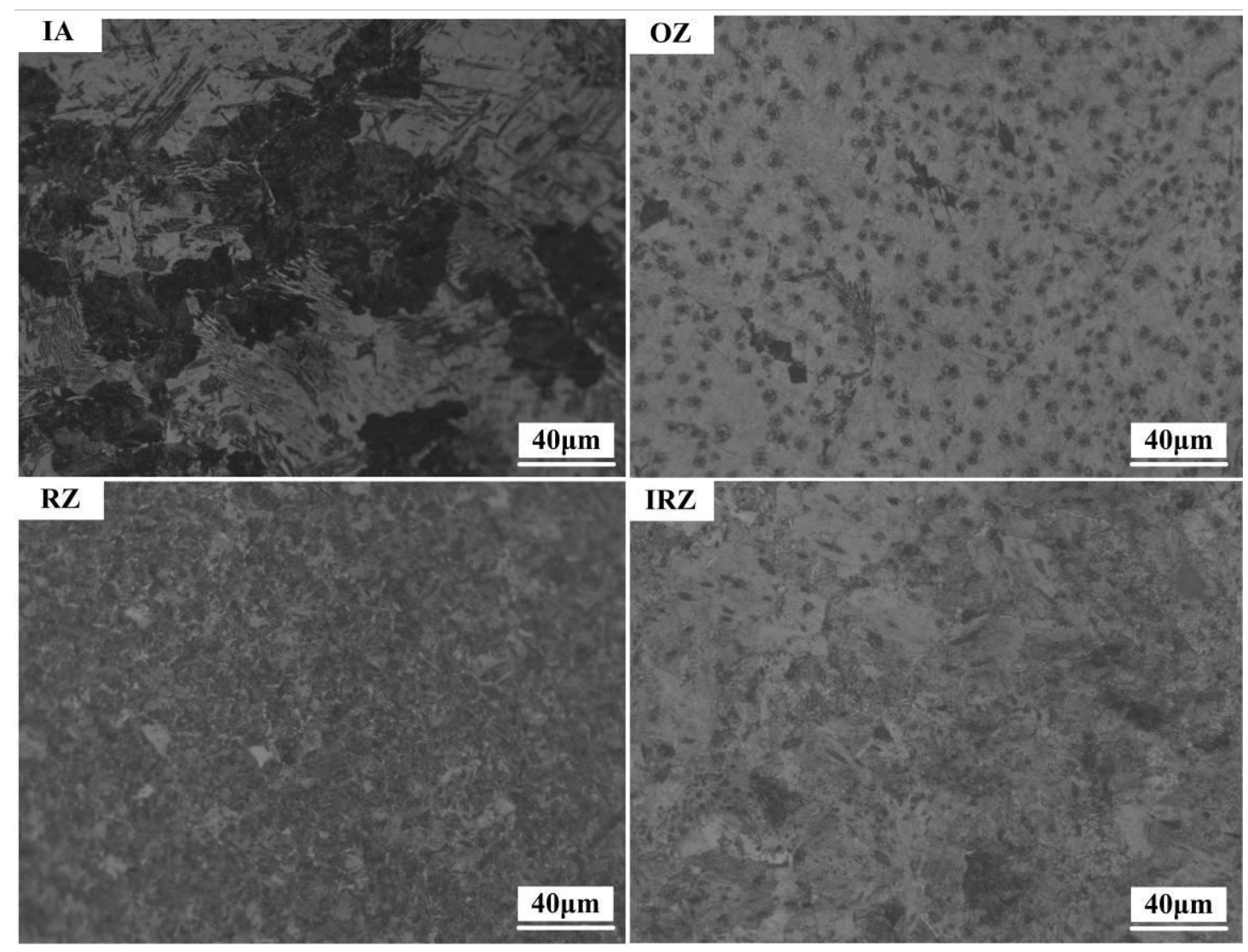

Fig. 5. The microstructure of flash welding joint based on welding process (I) 

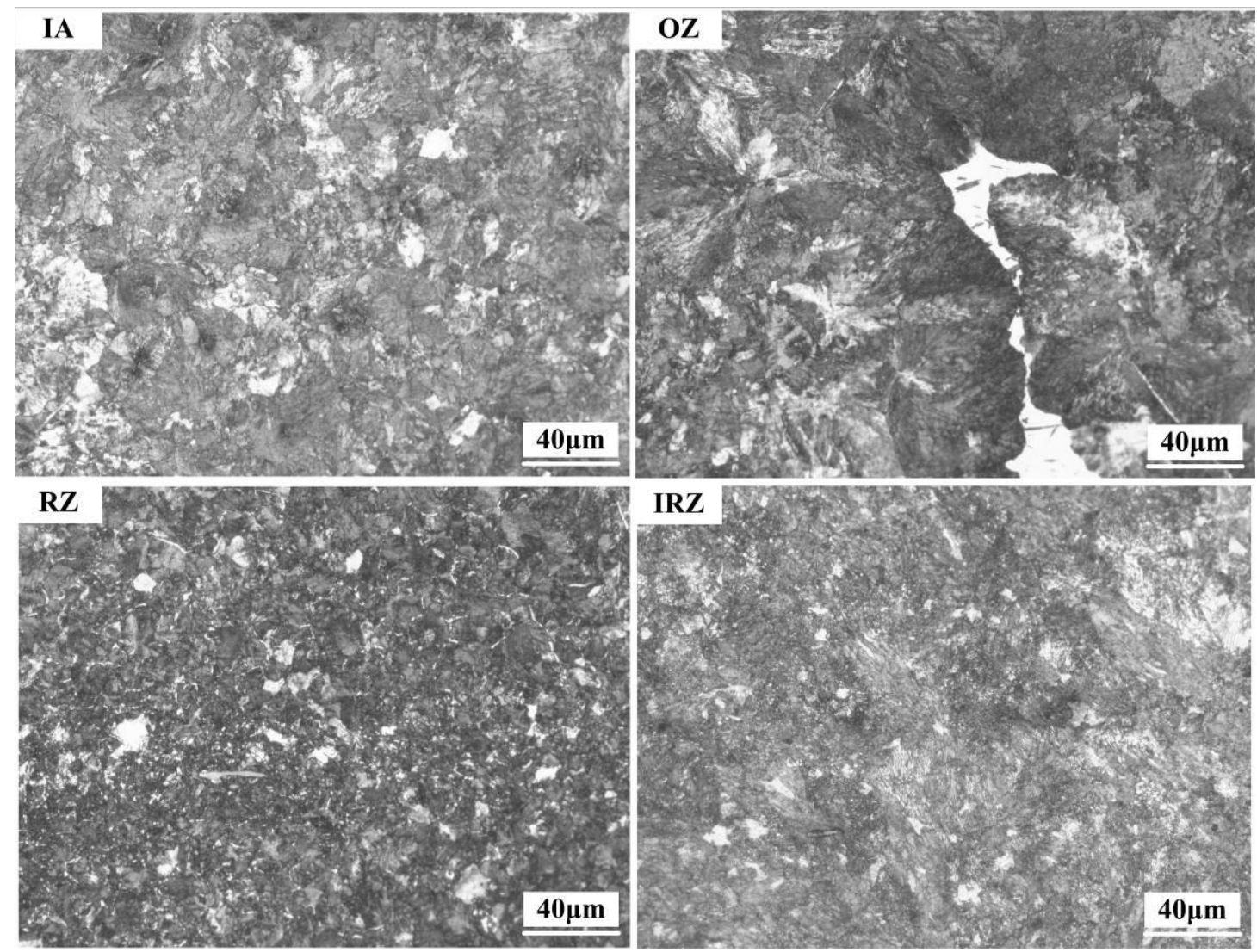

Fig. 6. The microstructure of flash welding joint based on welding process (II) 


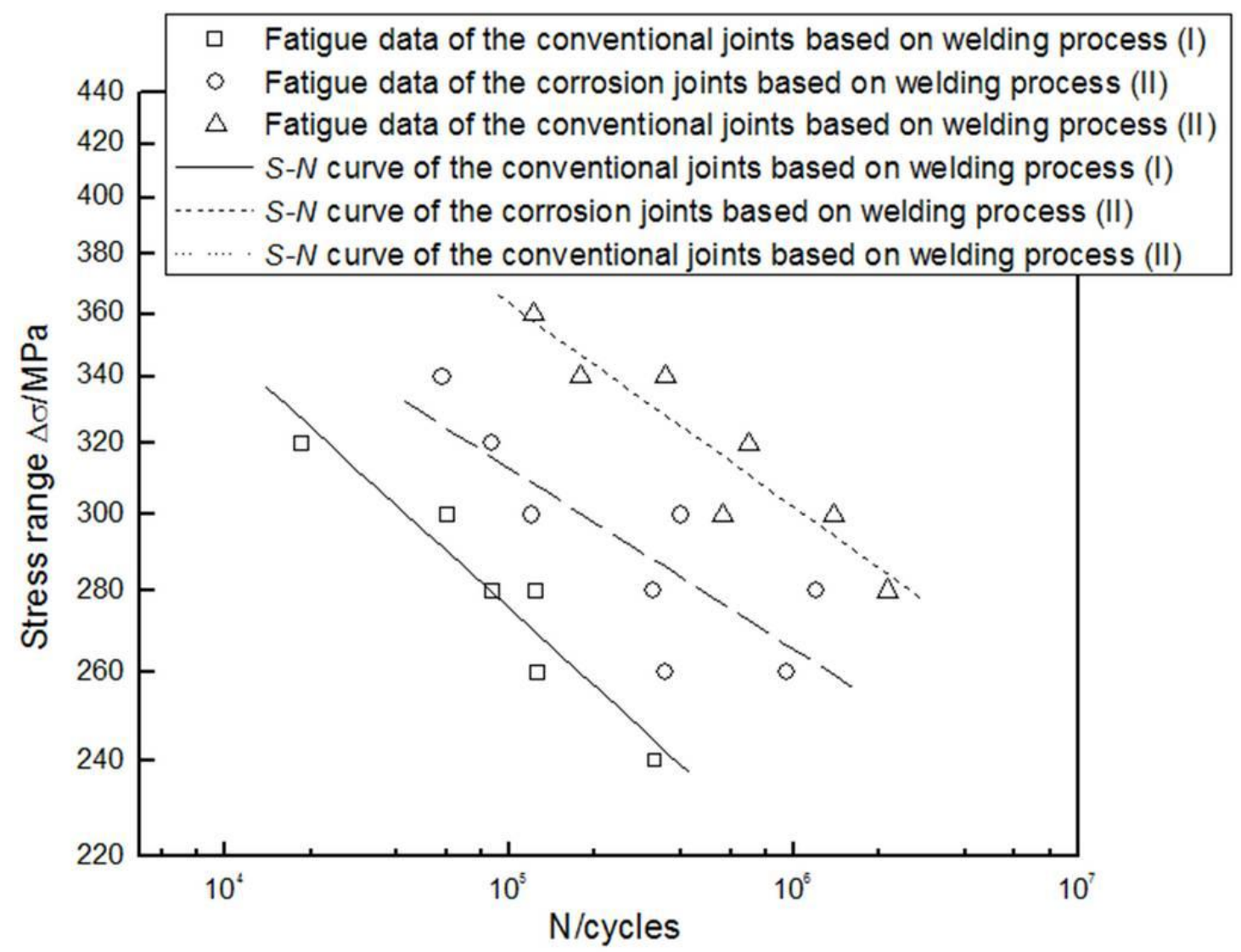

Fig. 7. $S$ - $N$ curves of joints under the condition of three welding processes 


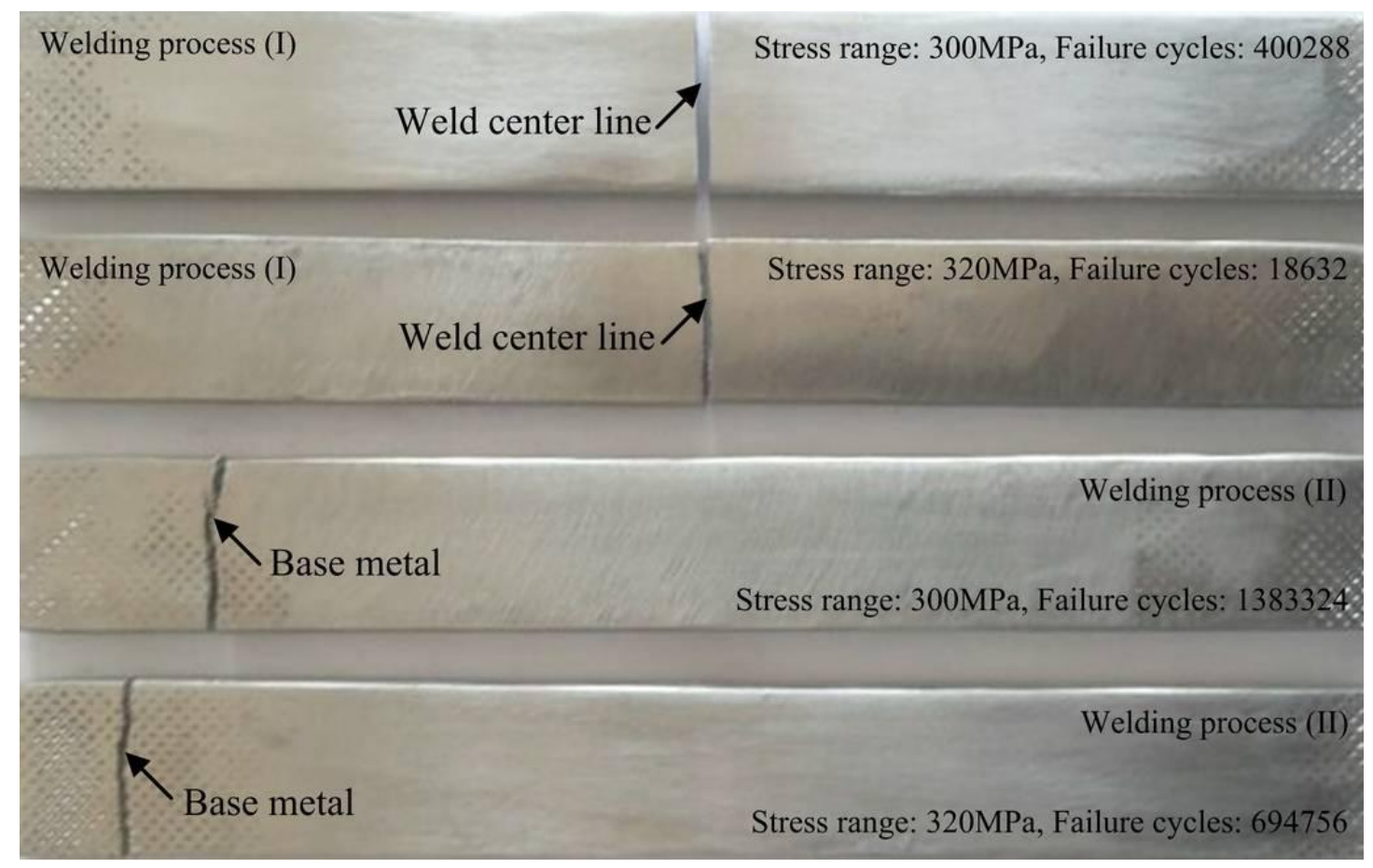

Fig. 8. Fatigue fracture location of the joints based on welding process (I) and (II) 


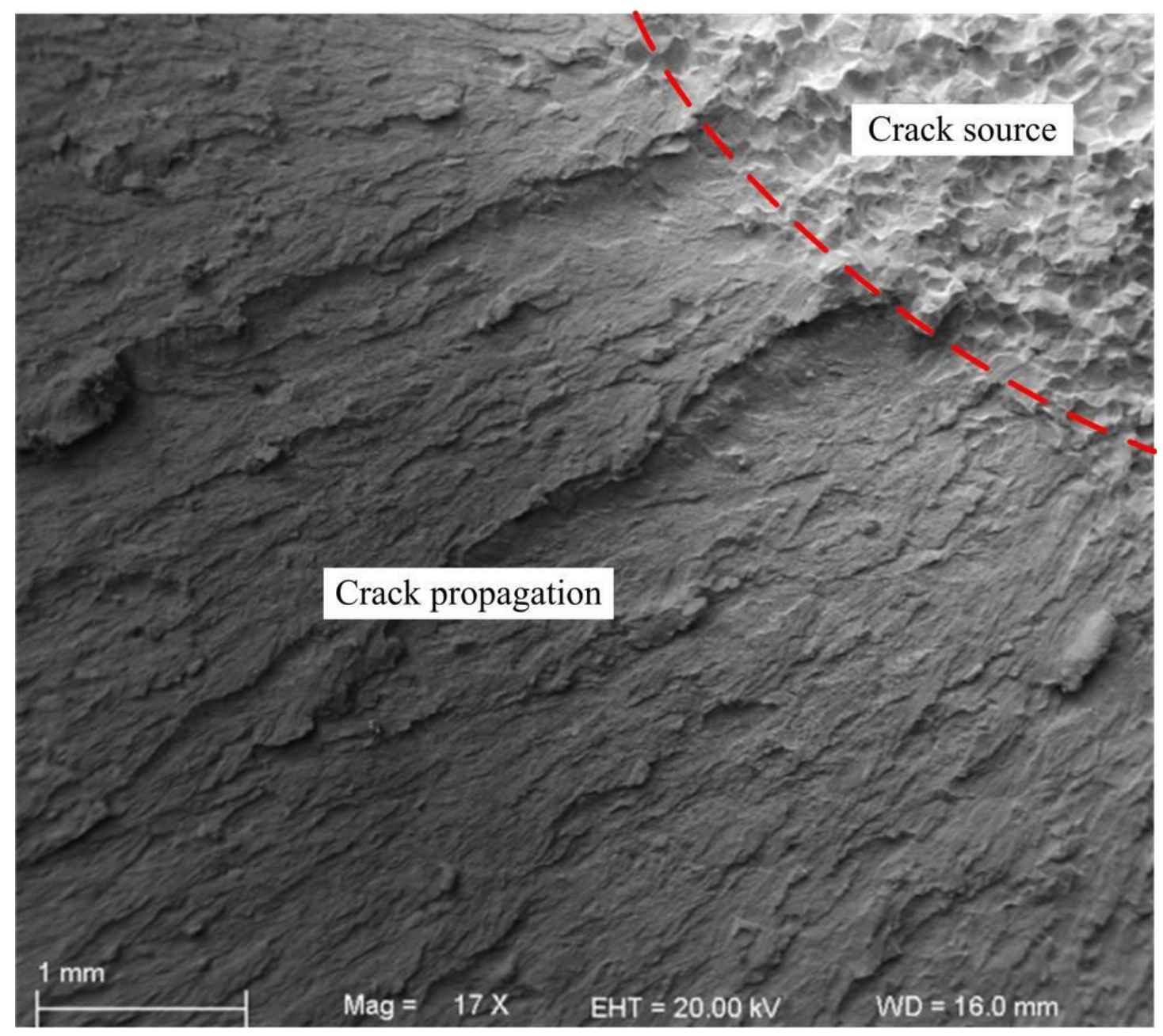

Fig. 9. SEM photograph of fatigue fracture for the joints based on welding process (I) 


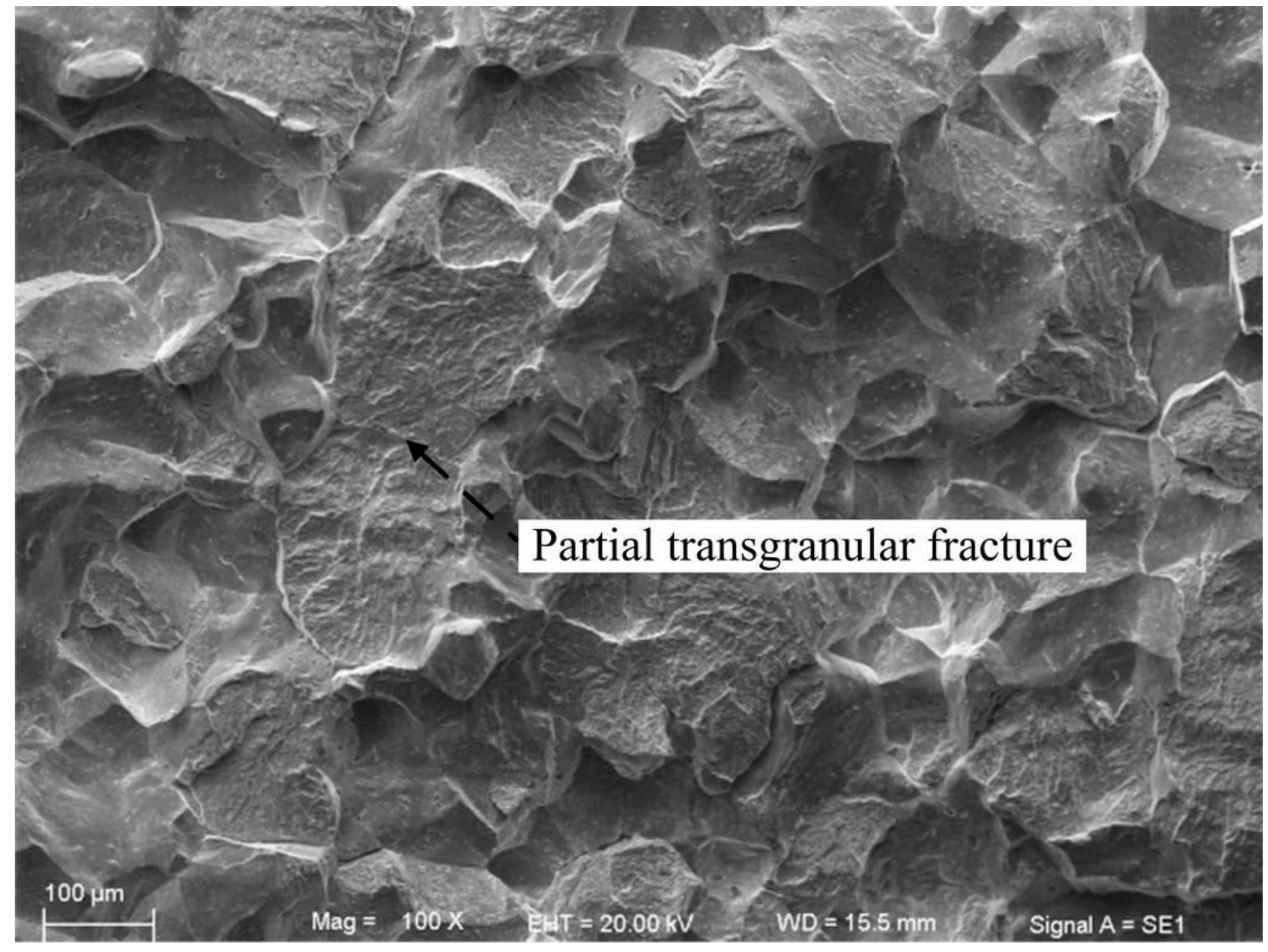

Fig. 10. SEM photograph of fatigue crack source region for the joints based on

welding process (I) 


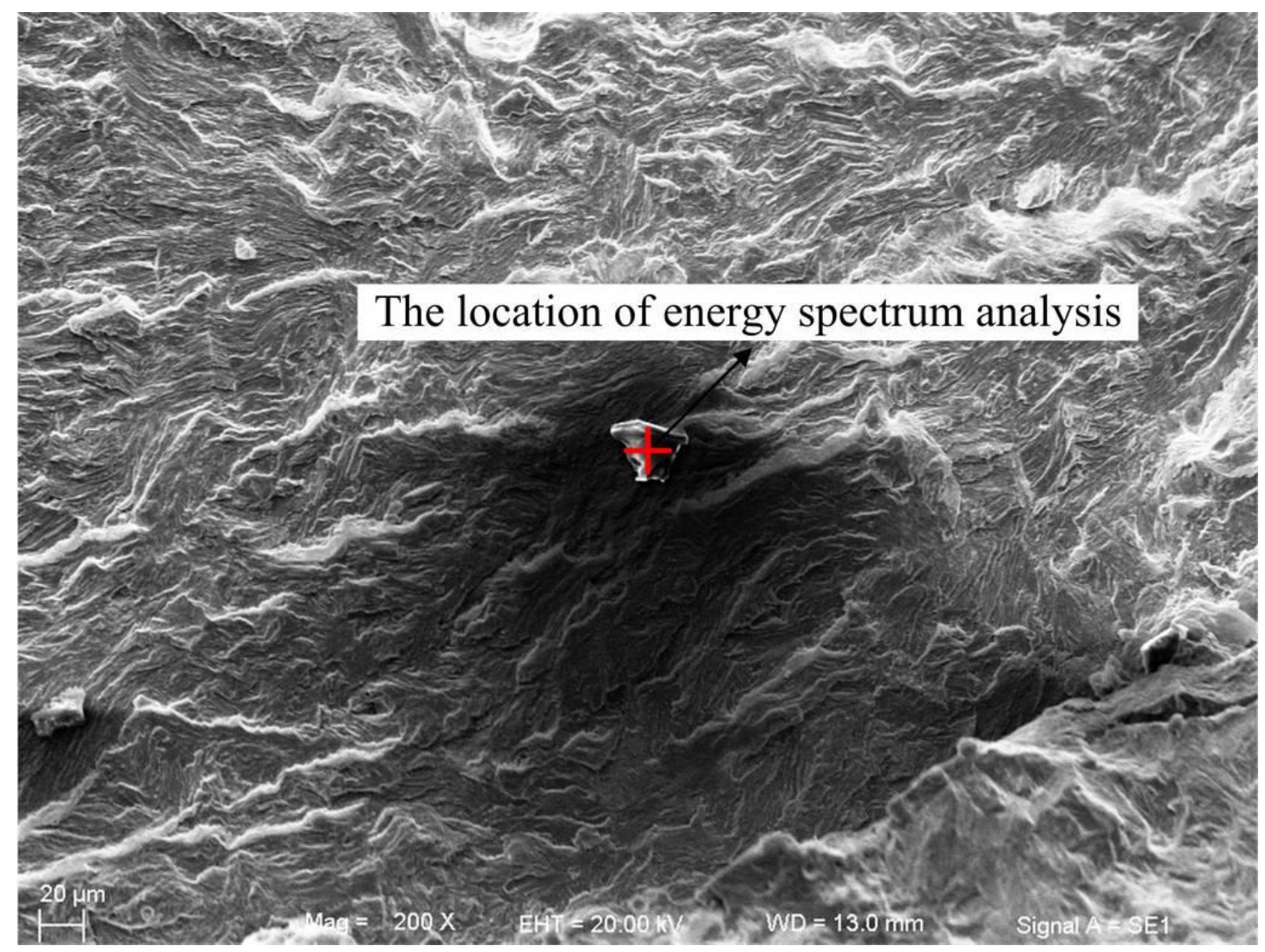

Fig. 11. SEM photograph of fatigue crack propagation region for the joints based on

welding process (I) 


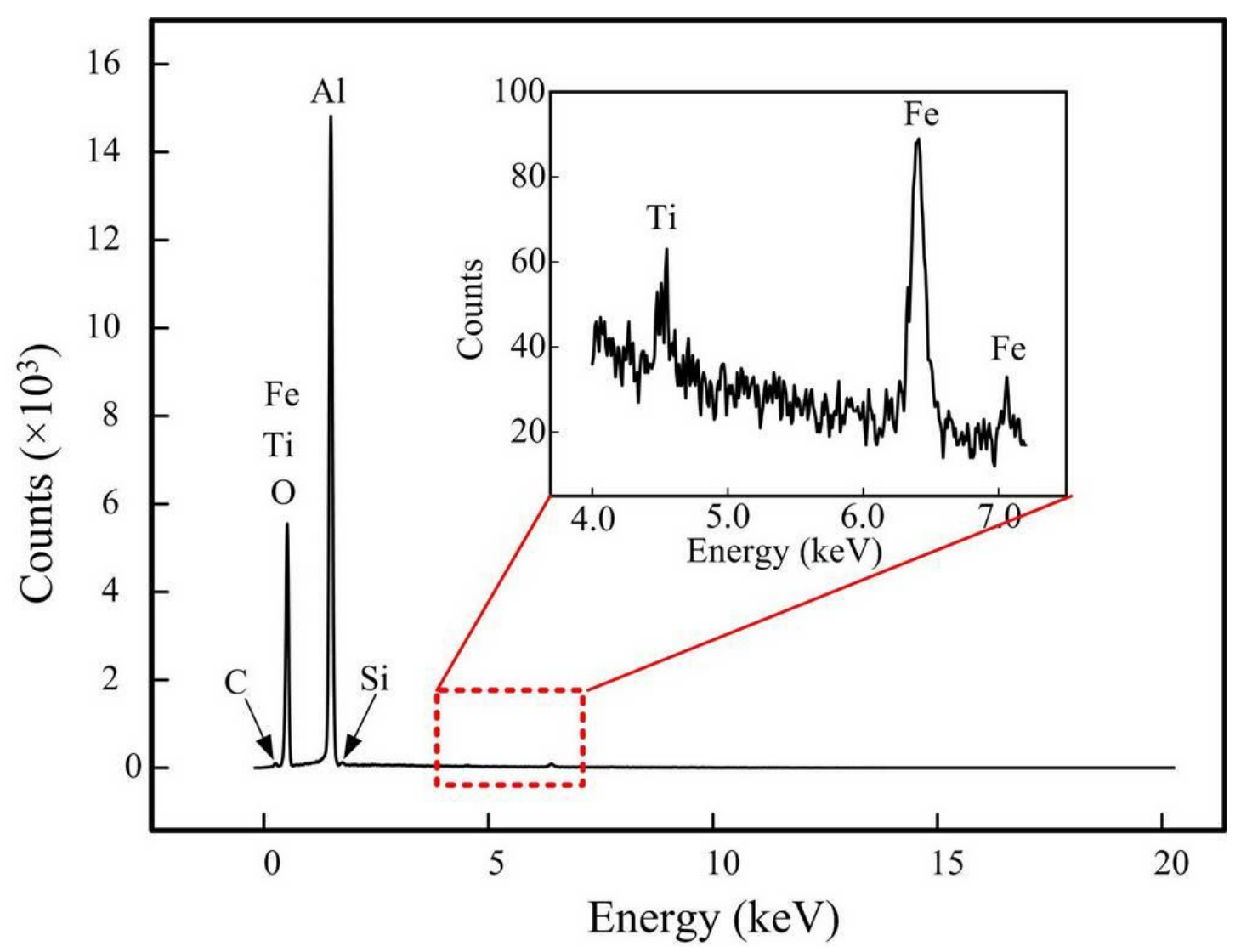

Fig. 12. The energy spectrum analysis for fatigue crack propagation region for the joints based on welding process (I) 


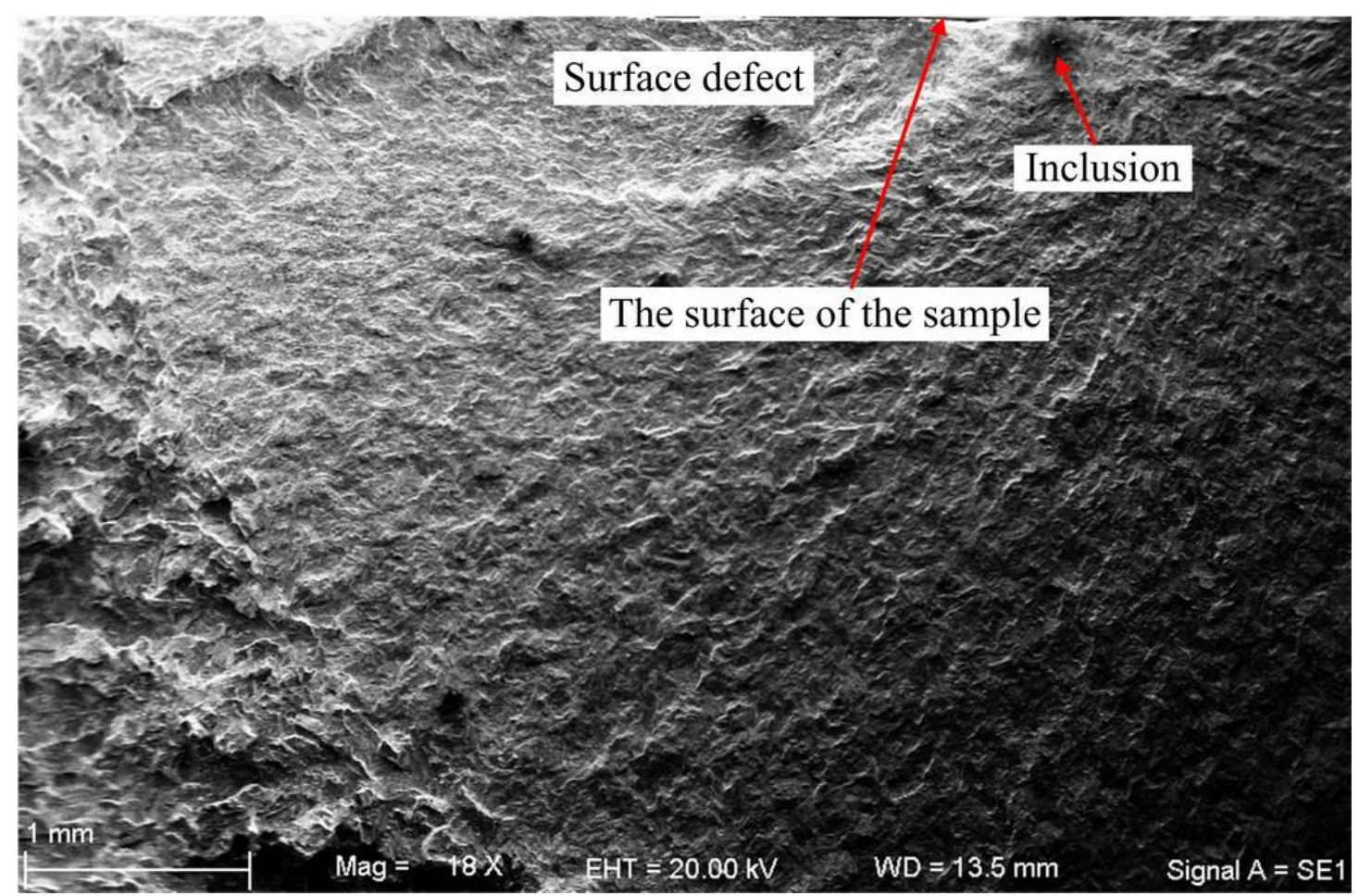

Fig. 13. SEM photograph of fatigue crack source region for the joints based on

welding process (II) 


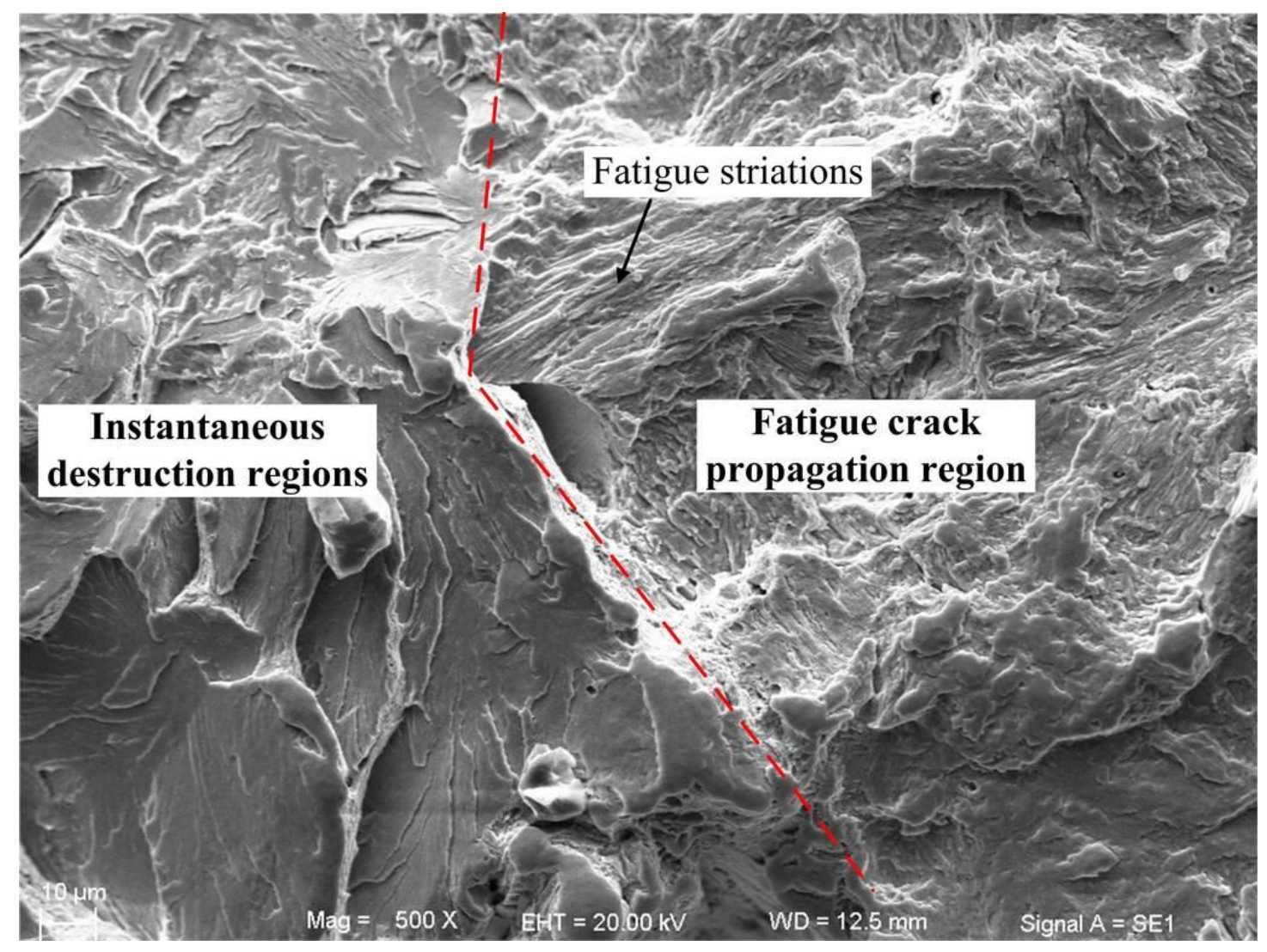

Fig. 14. SEM photograph of fatigue crack propagation region and instantaneous 


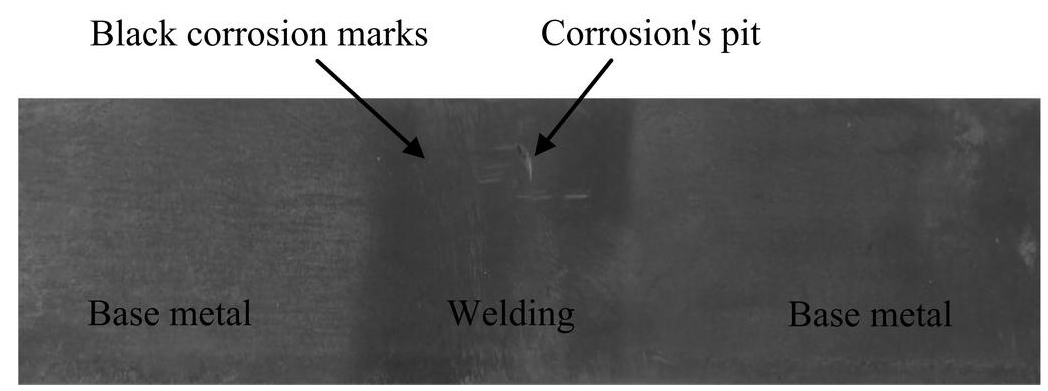

Fig. 15. The lateral surface of corrosion joint 


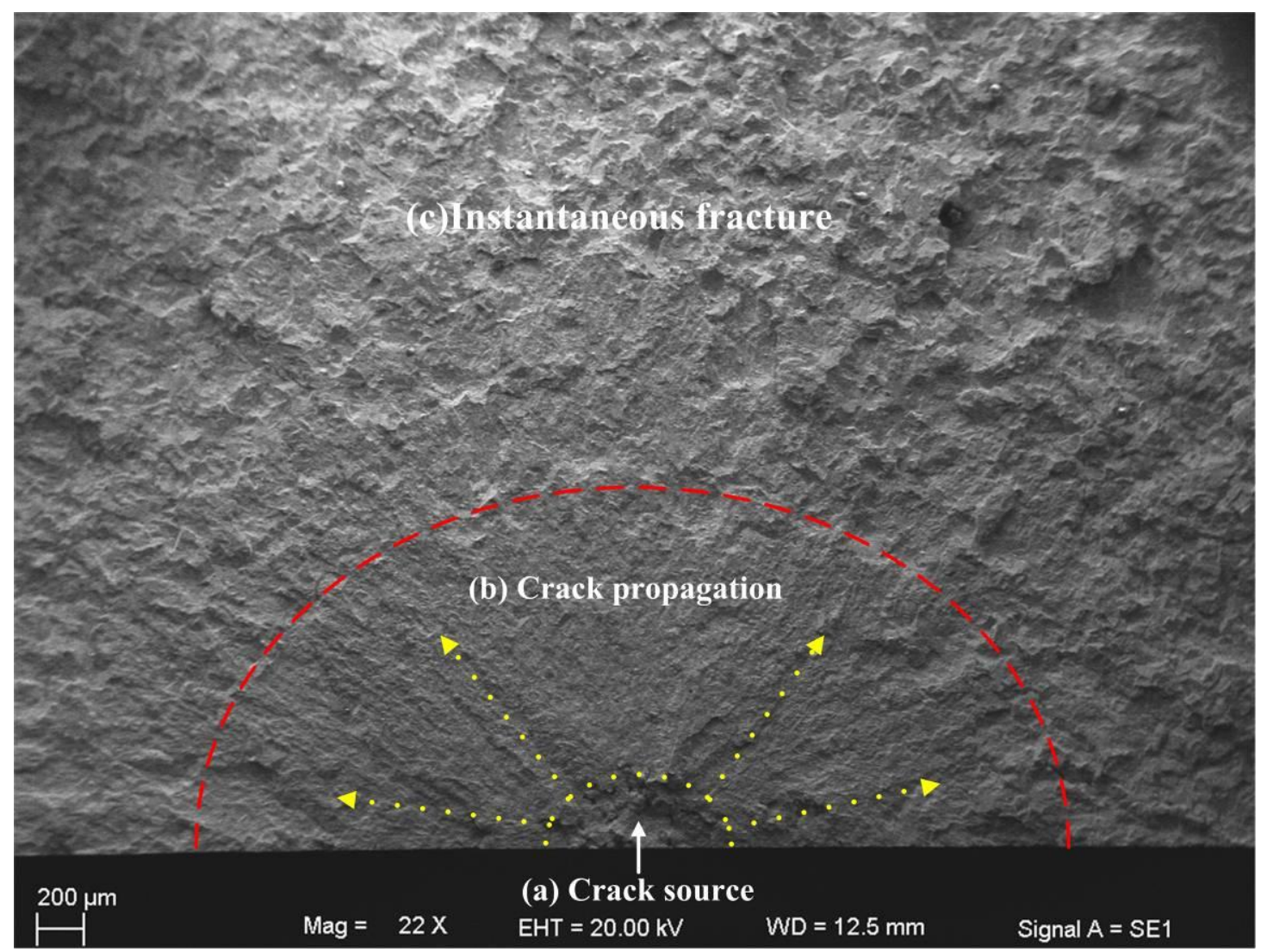

Fig. 16. SEM photograph of fatigue fracture for the corrosion joint based on welding process (II) 


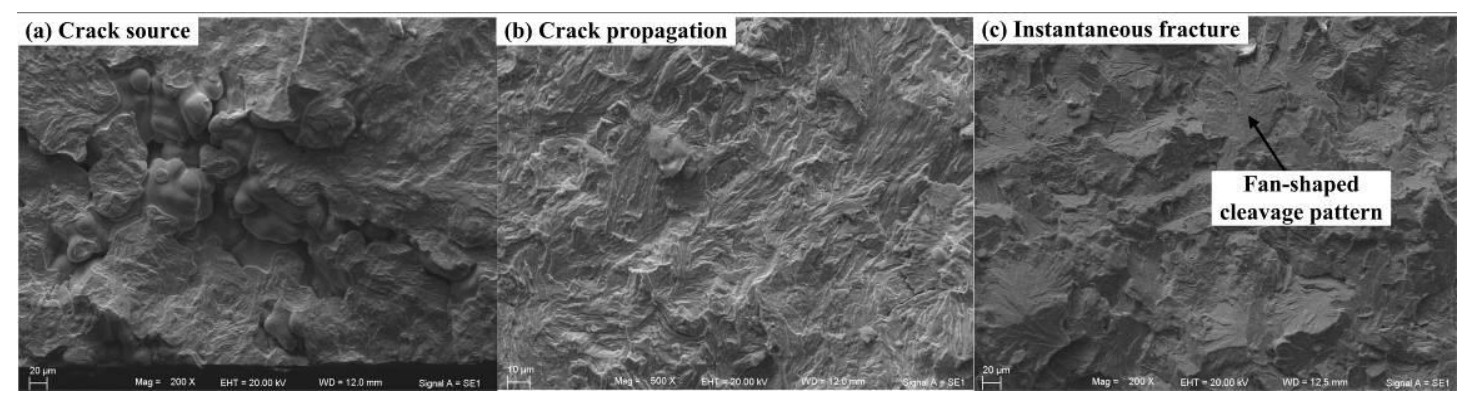

Fig. 17. SEM macrophotograph of three regions corresponding to

Fig. 16(a), (b) and (c) 


\section{Tables}

Table 1. Chemical composition (wt.\%) of U75V rail steel

Table 2. Mechanical properties of U75V rail steel

Table 3. Welding parameters of two welding processes

Table 4. The composition of artificial seawater

Table 5. The values of $\mathrm{m}$ and $C$ obtained from fitted $S-N$ curves and Eq. (1) 
Table 1. Chemical composition (wt.\%) of U75V rail steel

\begin{tabular}{ccccccccc}
\hline Composition & $\mathrm{C}$ & $\mathrm{Si}$ & $\mathrm{Mn}$ & $\mathrm{P}$ & $\mathrm{S}$ & $\mathrm{Nb}$ & $\mathrm{Al}$ & $\mathrm{V}$ \\
\hline Content & 0.79 & 0.56 & 0.90 & 0.12 & 0.08 & 0.02 & 0.03 & 0.55 \\
\hline
\end{tabular}


Table 2. Mechanical properties of U75V rail steel

\begin{tabular}{ccccc}
\hline Base metal & $\begin{array}{c}\text { Yield strength } \\
(\mathrm{MPa})\end{array}$ & $\begin{array}{c}\text { Tensile strength } \\
(\mathrm{MPa})\end{array}$ & $\begin{array}{c}\text { Elongation } \\
(\%)\end{array}$ & $\begin{array}{c}\text { Hardness value } \\
(\mathrm{HB})\end{array}$ \\
\hline U75V & 596 & 1062 & 10 & 307 \\
\hline
\end{tabular}

Table 3. Welding parameters of two welding processes

\begin{tabular}{cccccc}
\hline $\begin{array}{c}\text { Welding } \\
\text { process }\end{array}$ & Voltage/V & $\begin{array}{c}\text { Flash allowance } \\
/ \mathrm{mm}\end{array}$ & $\begin{array}{c}\text { Upset pressure } \\
/ \mathrm{MPa}\end{array}$ & $\begin{array}{c}\text { Upset allowance } \\
/ \mathrm{mm}\end{array}$ & $\begin{array}{c}\text { Flash rate } \\
/ \mathrm{mm} / \mathrm{s}\end{array}$ \\
\hline (I) & 4.42 & 7.5 & 13 & 2.5 & 0.18 \\
(II) & 4.40 & 7.5 & 25 & 2.5 & 0.20 \\
\hline
\end{tabular}


Table 4. The composition of artificial seawater

\begin{tabular}{cc}
\hline The types of salt & $\begin{array}{c}\text { The concentration of salt in } \\
\text { artificial seawater/(g/L) }\end{array}$ \\
\hline $\mathrm{NaCl}$ & 105.00 \\
$\mathrm{MgCl}_{2}$ & 12.70 \\
$\mathrm{MgSO}_{4} \cdot 7 \mathrm{H}_{2} \mathrm{O}$ & 7.70 \\
$\mathrm{CaSO}_{4} \cdot 2 \mathrm{H}_{2} \mathrm{O}$ & 12.15 \\
$\mathrm{CaCO}_{3}$ & 0.5 \\
\hline
\end{tabular}

Table 5. The values of $\mathrm{m}$ and $C$ obtained from fitted $S-N$ curves and Eq. (1)

\begin{tabular}{ccc}
\hline Joint type & The value of $\mathrm{m}$ & The value of $C$ \\
\hline $\begin{array}{c}\text { The conventional joints } \\
\text { based on welding process (I) } \\
\text { the corrosion joints based on } \\
\text { welding process (II) } \\
\begin{array}{c}\text { the conventional joints based } \\
\text { on welding process (II) }\end{array}\end{array}$ & 9.785 & $7.55 \mathrm{e} 28$ \\
\hline
\end{tabular}

